\section{PTH-028 EFFECTIVENESS OF TEMPORARY DOSE INCREASE AT RECAPTURING RESPONSE IN PATIENTS ON MAINTENANCE INFLIXIMAB}

doi:10.1136/gut.2011.239301.429

P Irving,1,* M Sastrillo, J Duncan, ${ }^{1}$ S Anderson,1 J Sanderson' ${ }^{1}$ Gastroenterology, Guy's and St Thomas' Hospitals, London, UK

Introduction Biologic drugs are widely used in Crohn's disease, often with good effect. Unfortunately, even with scheduled maintenance therapy, secondary loss of response is common affecting approximately $10-15 \%$ of patients/ year. There are two main options for recapturing response; dose increase or interval reduction. Published data suggest that these strategies can recapture response in approximately $75 \%$ of patients. However, both of these strategies have cost implications. Anecdotal reports suggest that in patients losing response to regular infusions of infliximab (IFX) $5 \mathrm{mg} / \mathrm{kg}$, a temporary increase to $10 \mathrm{mg} / \mathrm{kg}$ for two infusions can lead to subsequent recapture of response at $5 \mathrm{mg} / \mathrm{kg}$. This strategy for dealing with loss of response to IFX was agreed with our PCTs and has been followed recently. The authors aimed to identify what proportion of patients were subsequently able to persist with IFX treatment at $5 \mathrm{mg} / \mathrm{kg}$.

Methods The authors performed a retrospective review of all patients with Crohn's disease who had received double doses of IFX for loss of response since January 2009. Demographic data, HBI prior to the first infusion at the higher dose and prior to the first infusion at the lower dose, and ability to continue on IFX at $5 \mathrm{mg} / \mathrm{kg}$ were reviewed.

Results To date, 18 patients (8M:10F, median age 32 (range 19-51)) have received double dose IFX for loss of response. Median disease duration was 5 years (range 1-40) and the median time to dose increase from starting IFX was 15 months (range 6-60). All had received standard induction doses of IFX at $5 \mathrm{mg} / \mathrm{kg}$ on weeks 0,2 and 6 and were on scheduled maintenance therapy. The dose interval prior to dose increase was 8 weeks for 16 patients and 6 weeks for 2.12 patients were on concurrent immunomodulators and 6 were not 4 - intolerance, 2 - patient choice). To date, full outcome data are available for 11 subjects. Dose increase was effective in most patients in the short term with the median HBI falling from 7 prior to the first infusion at $10 \mathrm{mg} / \mathrm{kg}$, to 3.5 prior to the first infusion back at the standard dose $(5 \mathrm{mg} / \mathrm{kg})$. However, the majority $(8 / 11)$ required transfer onto adalimumab. Six patients who swapped to adalimumab did so prior to, or after one reinfusion of standard dose IFX and two patients after two infusions. Of the three patients who were able to recapture response, two have had three infusions at $5 \mathrm{mg} / \mathrm{kg}$ and one patient has had seven. Conclusion There are clear drug cost advantages to temporary dose increase over permanent dose increase or interval reduction. However, this experience suggests that the ability to maintain patients on IFX using this strategy is likely inferior to permanent changes in dose or treatment interval.

Competing interests PI, Speaker bureau with MSD, Abbott; MS, None declared; JD, None declared; SA, None declared; JS, None declared.

Keywords inflammatory bowel disease, infliximab. 